\title{
An evaluation of sucrose as a possible contaminant in e-liquids for electronic cigarettes by hydrophilic interaction liquid chromatography-tandem mass spectrometry
}

\author{
Pawel Kubica • Andrzej Wasik • Agata Kot-Wasik • \\ Jacek Namieśnik
}

Received: 3 December 2013 / Revised: 31 January 2014 / Accepted: 11 February 2014 / Published online: 25 March 2014

(C) The Author(s) 2014. This article is published with open access at Springerlink.com

\begin{abstract}
The influence of sucrose combustion products on smoking and nicotine addiction is still controversial because the presence of the sucrose may be treated as a source of aldehydes and organic acids. In e-liquids used as refills for electronic cigarettes, which are made primarily of poly(propylene glycol), glycerine and ethanol, sucrose may be present at trace levels, and its impact on mainstream smoke formation, and hence on human health and smoking/nicotine addiction is unknown. An analytical method was developed where highperformance liquid chromatography in hydrophilic interaction liquid chromatography mode and tandem mass spectrometry were used for fast and simple determination of sucrose and other saccharides in e-liquids for electronic cigarettes. Minimal effort was required in the sample preparation step, and satisfactory results were obtained, and the sample matrix had an insignificant impact. The chromatographic separation was done using an Ascentis Express OH5 column $(150 \mathrm{~mm} \times$ $2.1 \mathrm{~mm}, 2.7 \mu \mathrm{m})$. The coefficients of variation for within-day precision for three concentrations were $2.4 \%, 1.6 \%$ and $2.3 \%$, and the between-day coefficients of variation for a single concentration were $2.1 \%, 2.5 \%$ and $1.7 \%$ measured on the next 3 days. The detection limit was $0.73 \mu \mathrm{g} / \mathrm{g}$, and the sucrose content in e-liquids ranged from 0.76 to $72.93 \mu \mathrm{g} / \mathrm{g}$ among 37 samples. Moreover, with the method presented it is possible to determine the presence of other saccharides such as fructose, glucose, maltose and lactose. However, only sucrose was found in all samples of e-liquids. The proposed method is rapid, simple and reliable in terms of highperformance liquid chromatography coupled with tandem mass spectrometry.
\end{abstract}

P. Kubica $(\triangle) \cdot$ A. Wasik · A. Kot-Wasik · J. Namieśnik Department of Analytical Chemistry, Chemical Faculty,

Gdańsk University of Technology,

Narutowicza 11/12, 80-233 Gdańsk, Poland

e-mail: pawel.kubica.pg@gmail.com
Keywords Electronic cigarettes $\cdot$ Hydrophilic interaction liquid chromatography-tandem mass spectrometry . Carbohydrates

\section{Introduction}

The use of electronic cigarettes (e-cigarettes) as an alternative to traditional tobacco smoking and as part of therapy in nicotine and smoking addiction is becoming more and more popular. In our previous research, we proved that not all liquids for e-cigarettes marked as nicotine-free are actually free of nicotine [1]. Sucrose is a popular additive in tobacco products and is commonly used in the production processes and to enhance the taste and flavour of the tobacco. Moreover, sucrose occurs naturally in tobacco leaves [2-4] and can be determined by liquid chromatography combined with mass spectrometry [5] or by other techniques [6]. The exact mechanism of the formation of aldehydes and organic acids during combustion of sucrose and other sugars in tobacco is still not fully understood $[7,8]$. However, it is known that during this process organic acids and aldehydes may be formed [3, 9-12]. Aldehydes coming from sugars during the combustion of tobacco may have the reinforcing effect responsible for increased addiction to nicotine and smoking $[9,13]$. The high temperature during the combustion of tobacco (from 600 to $900{ }^{\circ} \mathrm{C}$ during drawing) is responsible for the formation of aldehydes and organic acids. The working temperature of the heating element of e-cigarettes is variable owing to the cooling of inhaled air flow [14]. From one point of view, this temperature may seem too low (around $250{ }^{\circ} \mathrm{C}$ ) to lead to the formation of aldehydes and organic acids, but there are reports $[3,15]$ indicating fairly quick formation of aldehydes from sucrose during cigarette smoking even at temperatures as low as $200{ }^{\circ} \mathrm{C}$. Furthermore, more than ten different aldehydes 
were detected in e-cigarette aerosol [16]. Despite this, the temperature is high enough to evaporate the main ingredient, which is poly(propylene glycol), with a boiling temperature of around $188^{\circ} \mathrm{C}$. All of the e-liquids available on the market are based on poly(propylene glycol) (above $80 \%$ ), glycerine and even ethanol (from 5 to $15 \%$ ) according to the labels attached. What is more, none of the labels of e-liquids on the market state that the products contain sucrose or may contain it at a trace level.

The purpose of the project was to develop a rapid and simple method for the evaluation of sucrose content in eliquids by hydrophilic interaction liquid chromatography (HILIC) and tandem mass spectrometry (MS/MS) with electrospray ionization and multiple reaction monitoring. The proposed analytical method allows the determination of the sucrose content in less than $4 \mathrm{~min}$, with minimal effort required for sample preparation.

\section{Materials and methods}

\section{Chemicals}

Standards of sucrose, glucose, fructose, maltose, lactose and raffinose as well as ammonium formate were purchased from Sigma-Aldrich (St. Louis, USA). High-performance liquid chromatography (HPLC) grade acetonitrile was purchased from Merck (Darmstadt, Germany). Ultrapure water was obtained with the use of an HLP5 system from Hydrolab (Wiślina, Poland).

\section{Samples}

Thirty-seven samples from different producers of popular ecigarettes were purchased on the local market. The labels attached to the products did not contain any information about carbohydrate content.
Preparation of standards and calibration solutions

Stock solutions of sucrose, glucose, fructose, maltose, lactose and raffinose (used as an internal standard) were prepared by dissolving an appropriate amount of each in a mixture of acetonitrile and water (80:20). The final concentration of each carbohydrate was $50 \mu \mathrm{g} / \mathrm{mL}$. The purity of raffinose, with regard to the presence of sucrose, was tested, and no traces of sucrose were detected. All samples tested were raffinose-free, and therefore use of raffinose as an internal standard is acceptable. Calibration solutions were prepared by dilution of the stock solution with the mobile phase to obtain sucrose concentrations of $10,50,100,150,200$ and $400 \mathrm{ng} / \mathrm{mL}$, whereas the concentration of the internal standard was kept at $400 \mathrm{ng} / \mathrm{mL}$. All solutions were stored in a refrigerator at $4{ }^{\circ} \mathrm{C}$ and every week new solutions were made.

Sample preparation and preparation of fortified samples

Fifty milligrams of each sample was added to a $10-\mathrm{mL}$ volumetric flask. Internal standard solution $(40 \mu \mathrm{L})$ was added, and the flask was filled up to the mark with the acetonitrile-water (80:20) mixture. Fortified samples were prepared as follows: a randomly selected sample with sucrose content below the limit of detection (LOD) was spiked with the appropriate amount of sucrose standard to obtain 10,20 and $30 \mu \mathrm{g} / \mathrm{g}$ solutions (these correspond to 50,100 and $150 \mathrm{ng} / \mathrm{mL}$ after sample preparation). The fortified samples were used for repeatability and trueness (recovery) determination.

\section{MS/MS conditions}

All analyses were performed with a Q-Trap 4000 triplequadrupole mass spectrometer from Applied Biosystems (Foster City, CA, USA) with electrospray ionization in negative mode, using Analyst ${ }^{\circledR}$ 1.5.2. Analyte-specific multiple
Table 1 Optimal parameters for the ion transitions monitored and tandem mass spectrometry (MS/ $M S$ ) operational parameters

$D P$ declustering potential, $E P$ entrance potential, $C X P$ collision cell exit potential, $C E$ collision energy

${ }^{\mathrm{a}}$ Qualitative transition

\begin{tabular}{|c|c|c|c|c|c|}
\hline \multicolumn{6}{|c|}{ Parameters for the ion transitions monitored } \\
\hline Analyte & Pseudomolecular ion $\rightarrow$ fragment ion & $\mathrm{DP}(\mathrm{V})$ & $\mathrm{EP}(\mathrm{V})$ & $\mathrm{CXP}(\mathrm{V})$ & $\mathrm{CE}(\mathrm{V})$ \\
\hline \multirow[t]{2}{*}{ Sucrose } & $341.0 \rightarrow 179.1$ & -100 & -10 & -5 & -20 \\
\hline & $341.0 \rightarrow 89.0^{\mathrm{a}}$ & & & -5 & -26 \\
\hline Glucose & $178.9 \rightarrow 88.9$ & -75 & -10 & -13 & -10 \\
\hline Fructose & $178.9 \rightarrow 88.9$ & -50 & -10 & -3 & -12 \\
\hline Maltose/lactose & $341.3 \rightarrow 160.7$ & -80 & -10 & -17 & -10 \\
\hline Raffinose & $503.2 \rightarrow 178.9$ & -125 & -10 & -13 & -30 \\
\hline \multicolumn{6}{|c|}{ MS/MS operation parameters } \\
\hline Curtain gas (psi) & Temperature $\left({ }^{\circ} \mathrm{C}\right)$ & \multicolumn{2}{|c|}{ Nebulizer gas (psi) } & \multicolumn{2}{|c|}{ Turbo gas (psi) } \\
\hline 20 & 550 & \multicolumn{2}{|l|}{50} & \multicolumn{2}{|l|}{40} \\
\hline
\end{tabular}


reaction monitoring conditions and ion source parameters were determined using an appropriate Analyst ${ }^{\circledR}$ feature, by the infusion of a $200 \mathrm{ng} / \mathrm{mL}$ solution of each carbohydrate, and in flow injection mode, respectively. Optimum detection conditions are presented in Table 1.
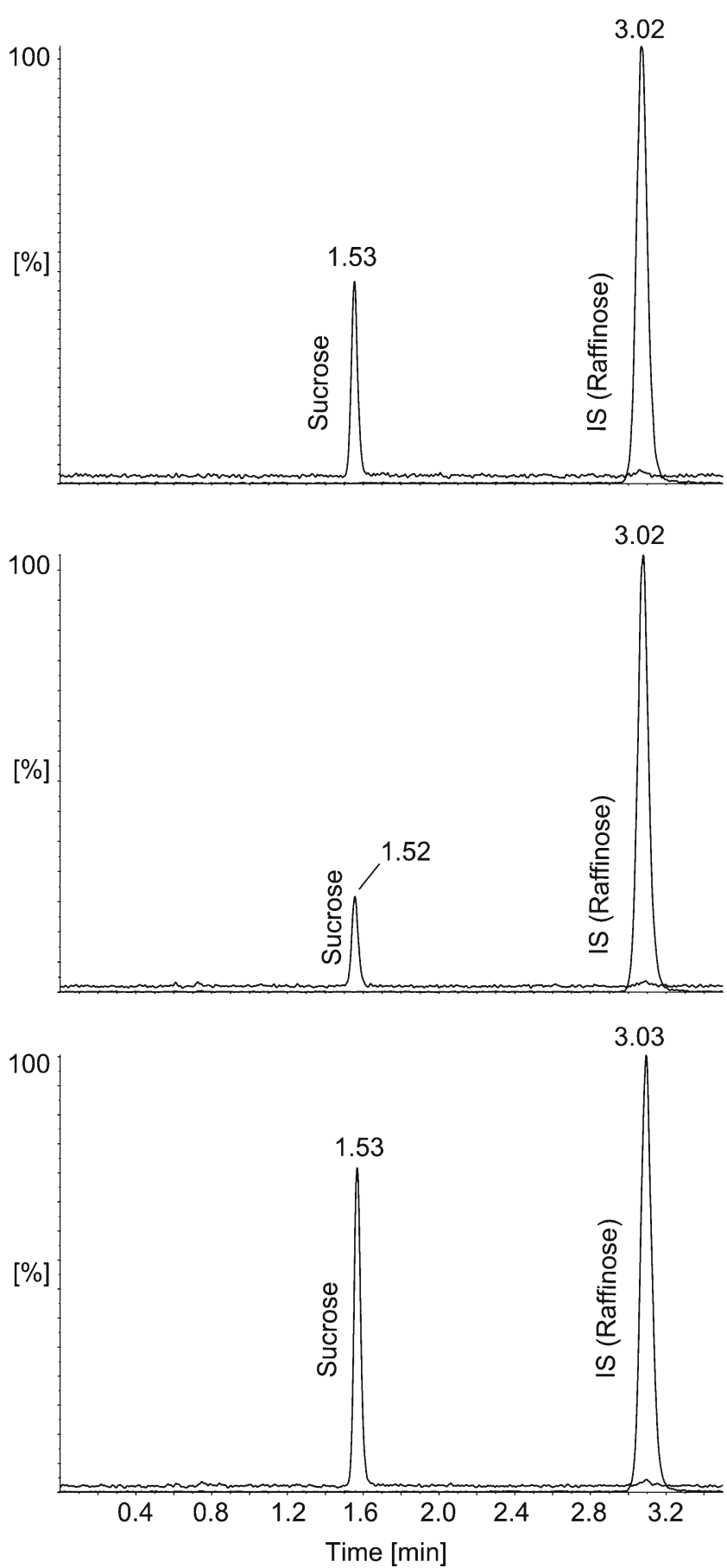

Fig. 1 Examples of chromatograms obtained in hydrophilic interaction liquid chromatography (HILIC) mode. From the top: mixture of standards sucrose $(100 \mathrm{ng} / \mathrm{mL})$ and raffinose $(400 \mathrm{ng} / \mathrm{mL})$, chromatogram of real sample C cherry (sucrose concentration $8.00 \mu \mathrm{g} / \mathrm{g}$ ), chromatogram of real sample D coffee (sucrose concentration $40.82 \mu \mathrm{g} / \mathrm{g}$ ). IS internal standard

\section{HPLC conditions}

The chromatographic separation was performed using the HPLC-MS/MS system consisting of a pump, degasser, autosampler and column oven from the Agilent 1200 series. The separation of analytes was achieved in the HILIC mode using an Ascentis Express column (Supelco, Bellefonte, PA, USA; $150 \mathrm{~mm} \times 2.1 \mathrm{~mm}, 2.7 \mu \mathrm{m}$, pore size $80 \AA$ ). The column oven temperature was set to $35{ }^{\circ} \mathrm{C}$. The mobile phase contained acetonitrile (solvent $\mathrm{A}$ ) and ammonium formate buffer (solvent B) adjusted to $\mathrm{pH}$ 6.8. The presence of ammonium formate is necessary to obtain narrow and symmetrical peaks. Too high a concentration of buffer will suppress the detector signal, and therefore its concentration was kept to a minimum, i.e. $2 \mathrm{mM}$. The separation of sugars was performed in the isocratic mode $(80 \%$ solvent $\mathrm{A}$ and $20 \%$ solvent B) at a flow rate of $0.7 \mathrm{~mL} / \mathrm{min}$. The injection volume was set to $5 \mu \mathrm{L}$. The total time of the chromatographic run was $3.5 \mathrm{~min}$. Chromatograms of standards (sucrose and raffinose) and chromatograms of selected real samples are presented in Fig. 1.

\section{Results and discussion}

The possible presence of other sugars in e-liquids

Most of the disaccharides are built of monomers such as glucose, galactose and fructose. This means that they will generate the same pseudomolecular and fragmentation ions during MS/MS. In fact, only the difference in the retention times between different sugars allows their identification. The samples of e-liquids were tested for the presence of two disaccharides (lactose and maltose) and two common monosaccharides (fructose and glucose) in order to exclude their possible coelution with sucrose. The mixture containing each sugar at $200 \mathrm{ng} / \mathrm{mL}$ was analysed under the conditions described in "HPLC conditions". The chromatogram presenting the separation of standards is shown in Fig. 2. Under the proposed HPLC conditions, sucrose is baseline-separated from other sugars; hence, they will not interfere with its quantitative determination. None of the 37 samples analysed were found to contain sugars other than sucrose.

Within-laboratory validation

\section{Analytical figures of merit}

A six-point calibration curve was constructed using raffinose as an internal standard, and each calibration solution (see "Preparation of standards and calibration solutions") was analysed in triplicate. The curve was linear in the range of concentrations studied. The LOD was calculated with the 
Fig. 2 Chromatogram of a mixture of analytes: fructose, glucose, sucrose, maltose, lactose and raffinose (each at $200 \mathrm{ng} / \mathrm{mL}$ ) detected by negative electrospray ionization tandem mass spectrometry in HILIC mode

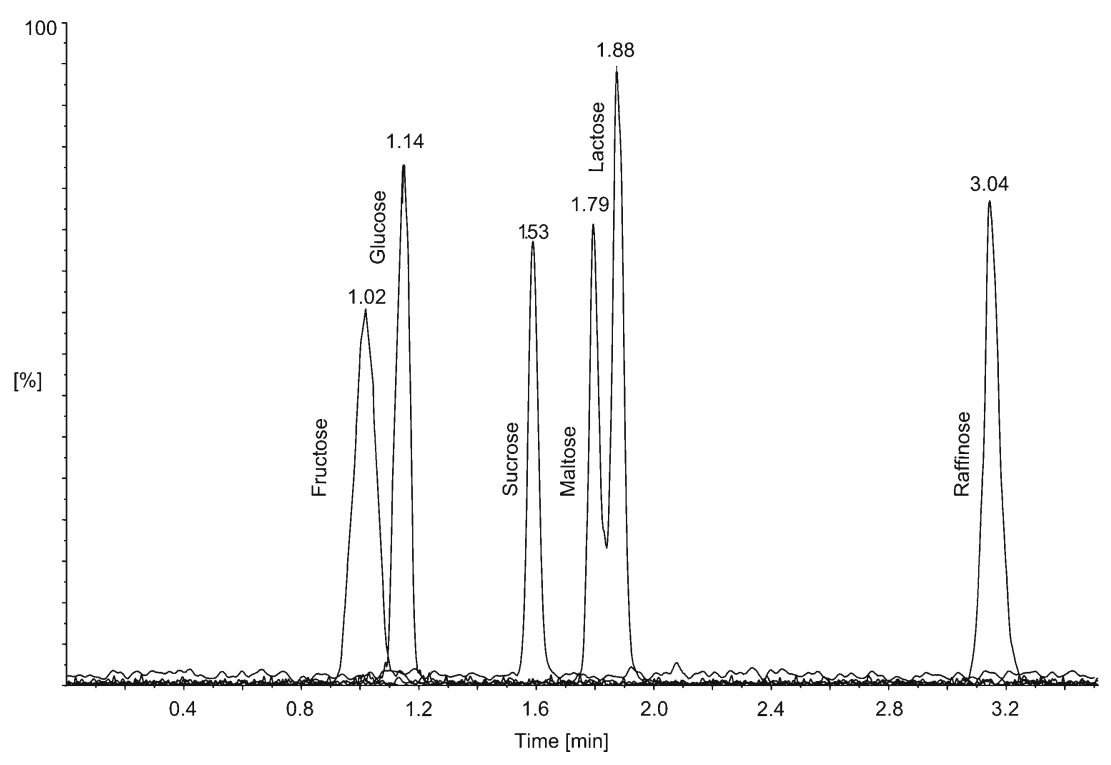

equation $\mathrm{LOD}=3.3 S_{\mathrm{b}} / a$, where $S_{\mathrm{b}}$ is the standard deviation of the intercept and $a$ is the slope of the calibration curve. The limit of quantitation was calculated as three times the LOD. The LOD obtained $(0.73 \mu \mathrm{g} / \mathrm{g})$ is similar to $[17,18]$ or even lower $[19,20]$ than the values reported by others. Within-day precision was estimated by replicate $(n=6)$ analysis of samples fortified at three concentrations $(10,20$ and $30 \mu \mathrm{g} / \mathrm{g})$ on 1 day. Data obtained during the within-day precision investigation were also used to assess the trueness of the method. Intermediate (between-day) precision was verified by analysing the single fortified solution $(20 \mu \mathrm{g} / \mathrm{g})$ for three consecutive days. Again, each analysis was performed six times $(n=6)$.
As can be seen from Table 2, the recovery values at all spiking levels are close to $100 \%$, which means that no matrix effects or bias was observed. This allows the use of external calibration instead of a matrix-matched approach. The method also performs well in terms of precision. In no case was the coefficient of variation greater than $2.5 \%$.

\section{Analysis of real samples}

All samples were prepared according to the protocol described in "Sample preparation and preparation of fortified samples". Samples were chosen from among the most manufacturers

Table 2 Determination of sucrose in fortified e-liquid samples: calibration parameters, trueness and repeatability data

\begin{tabular}{|c|c|c|c|c|c|c|}
\hline Analyte & Calibration curve equation ( 6 point, $n=3$ ) & $S_{\mathrm{a}}^{\mathrm{a}}$ & $S_{\mathrm{b}}^{\mathrm{c}}$ & $R^{2 \mathrm{~d}}$ & $\mathrm{LOD}(\mu \mathrm{g} / \mathrm{g})$ & $\mathrm{LOQ}(\mu \mathrm{g} / \mathrm{g})$ \\
\hline \multirow[t]{11}{*}{ Sucrose } & $y=0.001746 x+0.0479$ & 0.000011 & 0.0019 & 0.9995 & 0.73 & 2.2 \\
\hline & \multicolumn{6}{|l|}{ Within-day precision ( 3 spiking levels, $n=6$ ) } \\
\hline & Spiking level $(\mu \mathrm{g} / \mathrm{g})$ & Recovery ${ }^{\mathrm{b}}(\%)$ & $\mathrm{CV}(\%)$ & & & \\
\hline & 10 & 101.4 & 2.4 & & & \\
\hline & 20 & 101.1 & 1.6 & & & \\
\hline & 30 & 98.3 & 2.3 & & & \\
\hline & \multicolumn{6}{|c|}{ Between-day precision ( 1 spiking level, $20 \mu \mathrm{g} / \mathrm{g}, n=6$ ) } \\
\hline & Day & Recovery $^{\mathrm{b}}(\%)$ & $\mathrm{CV}(\%)$ & & & \\
\hline & 1 & 99.6 & 2.1 & & & \\
\hline & 2 & 105.8 & 2.5 & & & \\
\hline & 3 & 102.9 & 1.7 & & & \\
\hline
\end{tabular}

$L O D$ limit of detection, $L O Q$ limit of quantitation, $S D$ standard deviation, $C V$ coefficient of variation

${ }^{\text {a }}$ Standard deviation of the slope

${ }^{\mathrm{b}}$ Calculated as the ratio between the mean concentration found from the calibration curve and the spiking level

${ }^{\mathrm{c}}$ Standard deviation of the constant term

${ }^{\mathrm{d}}$ Coefficient of determination 
and the popular brands available on the market. The content of sucrose in the samples analysed is presented in Table 3.

Only in four samples was the sucrose content below the LOD or $C_{\min }$ used for the construction of the calibration curve. These samples were reanalysed with less dilution $(5 \mathrm{~mL}$ instead of $10 \mathrm{~mL}$ ). There is no clear relationship between the sucrose content and the manufacturer. Among the samples of a given brand, one will find e-liquids that are almost sucrose-

Table 3 Concentration of sucrose in e-liquids for electronic cigarettes: analysis of real samples

\begin{tabular}{|c|c|c|}
\hline Company & Taste & Concentration of sucrose $\pm \mathrm{SD}(\mu \mathrm{g} / \mathrm{g})$ \\
\hline \multirow[t]{3}{*}{ A } & Black & $1.11 \pm 0.21$ \\
\hline & Cherry & $2.28 \pm 0.11$ \\
\hline & Menthol & $23.73 \pm 0.81$ \\
\hline \multirow[t]{6}{*}{ B } & Camel & $0.68^{\mathrm{a}}$ \\
\hline & Chocolate & $7.315 \pm 0.095$ \\
\hline & Grape & $5.04 \pm 0.28$ \\
\hline & Orange & $0.56^{\mathrm{a}}$ \\
\hline & Strawberry & $0.64^{\mathrm{a}}$ \\
\hline & Watermelon & $1.99 \pm 0.11$ \\
\hline \multirow[t]{9}{*}{$\mathrm{C}$} & Banana & $2.31 \pm 0.19$ \\
\hline & Camel & $10.89 \pm 0.14$ \\
\hline & Cherry & $8.006 \pm 0.024$ \\
\hline & Fruit mix & $5.62 \pm 0.37$ \\
\hline & Marlboro & $20.15 \pm 0.43$ \\
\hline & Menthol & $10.66 \pm 0.55$ \\
\hline & L\&M & $0.784 \pm 0.053$ \\
\hline & Red Bull & $19.06 \pm 0.34$ \\
\hline & Vanilla & $1.027 \pm 0.093$ \\
\hline \multirow[t]{10}{*}{$\mathrm{D}$} & Apple & $25.07 \pm 0.35$ \\
\hline & Camel & $1.211 \pm 0.052$ \\
\hline & Cherry & $8.65 \pm 0.36$ \\
\hline & Chocolate & $72.93 \pm 0.72$ \\
\hline & Coffee & $40.82 \pm 0.52$ \\
\hline & L\&M & $9.86 \pm 0.28$ \\
\hline & Marlboro & $13.11 \pm 0.20$ \\
\hline & Red Bull & $13.46 \pm 0.23$ \\
\hline & Strawberry & $8.22 \pm 0.14$ \\
\hline & Tobacco & $19.91 \pm 0.54$ \\
\hline \multirow[t]{2}{*}{ E } & Cherry & $0.62^{\mathrm{a}}$ \\
\hline & Coffee & $3.40 \pm 0.20$ \\
\hline \multirow[t]{5}{*}{$\mathrm{F}$} & Coffee & $0.76 \pm 0.12$ \\
\hline & Menthol & $26.23 \pm 0.29$ \\
\hline & Red Bull & $7.74 \pm 0.20$ \\
\hline & Tea & $22.25 \pm 0.46$ \\
\hline & Tobacco & $29.82 \pm 0.43$ \\
\hline \multirow[t]{2}{*}{ G } & Fruit mix & $1.80 \pm 0.13$ \\
\hline & Menthol & $11.67 \pm 0.35$ \\
\hline
\end{tabular}

${ }^{a}$ Informative value only, samples were reanalysed with less dilution (see the text for details) free together with others high in sucrose. For example, most of the samples from producer B are low in sucrose (less than $1 \mu \mathrm{g} / \mathrm{g}$ ), but there is an exception. Chocolate-flavoured eliquid was found to contain sucrose at a concentration of $7.3 \mu \mathrm{g} / \mathrm{g}$. The opposite situation can be observed in the case of producers $\mathrm{C}$ and $\mathrm{D}$. Here, most of the samples were found to be high in sucrose, but there were a few exceptions. Likewise, no direct relationship was found between the flavour and the sucrose content. Only in the case of mentholflavoured e-liquids was the sucrose content rather high in each sample.

\section{Conclusions}

The purpose of this project was to develop a simple, reliable and sensitive method for the determination of sucrose in eliquids with minimum effort for sample preparation. The method developed may be helpful in future research on ecigarettes. The main advantages of the method presented are the low LOD $(0.73 \mu \mathrm{g} / \mathrm{g})$ and the short analysis time, without the need to stabilize the column owing to the isocratic separation mode. The source of sucrose in e-liquids is unknown. One of the possibilities is that sucrose is a component of the flavour/taste additives, or it is a contaminant from the production process. Another possibility is that sucrose is extracted along with nicotine from tobacco leaves, although in such a case reducing sugars such as fructose and glucose should also be present. Still, there is much controversy about the safety of e-cigarettes, and the method developed may be helpful in quality control, or research on the impact of e-liquid content and the composition of e-cigarette aerosol.

Open Access This article is distributed under the terms of the Creative Commons Attribution License which permits any use, distribution, and reproduction in any medium, provided the original author(s) and the source are credited.

\section{References}

1. Kubica P, Kot-Wasik A, Wasik A, Namieśnik J (2013) "Dilute \& shoot" approach for rapid determination of trace amounts of nicotine in zero-level e-liquids by reversed phase liquid chromatography and hydrophilic interactions liquid chromatography coupled with tandem mass spectrometry-electrospray ionization. J Chromatogr A 1289: $13-18$

2. Leffingwell JC (1999) Leaf chemistry: basic chemical constituents of tobacco leaf and differences among tobacco types. In: Davis DL, Nielsen MT (eds) Tobacco: production chemistry and technology. Blackwell, Oxford, pp 265-284

3. Talhout R, Opperhuizen A, Amsterdam JGCV (2006) Sugars as tobacco ingredient: effects on mainstream smoke composition. Food Chem Toxicol 44:1789-1798 
4. Bates C, Jarvis M, Connolly G (1999) Tobacco additives: cigarette engineering and nicotine addiction. http://www.ash.org.uk/files/ documents/ASH_623.pdf

5. Clarke MB, Bezabeh DZ, Howard CT (2006) Determination of carbohydrates in tobacco products by liquid chromatography-mass spectrometry/mass spectrometry: a comparison with ion chromatography and application to product discrimination. J Agric Food Chem 54(6):1975-1981

6. Troje ZŠ, Fröbe Z, Perović Đ (1997) Analysis of selected alkaloids and sugars in tobacco extract. J Chromatogr A 775:101-107

7. Tomasik P, Pałasiński M, Wiejak S (1989) The thermal decomposition of carbohydrates. Part I. The decomposition of mono-, di-, and oligo-saccharides. Adv Carbohydr Chem Biochem 47:203-278

8. Tomasik P, Pałasiński M, Wiejak S (1989) The thermal decomposition of carbohydrates. Part II.* The decomposition of starch. Adv Carbohydr Chem Biochem 47:279-343

9. Talhout R, Opperhuizen A, van Amsterdam JGC (2007) Role of acetaldehyde in tobacco smoke addiction. Eur Neuropsychopharmacol 17:627-636

10. Seeman JI, Dixon M, Haussmann HJ (2002) Acetaldehyde in mainstream tobacco smoke: formation and occurrence in smoke and bioavailability in the smoker. Chem Res Toxicol 15(11):1331-1350

11. Seeman JI, Laffoon SW, Kassman AJ (2003) Evaluation of relationships between mainstream smoke acetaldehyde and "tar" and carbon monoxide yields in tobacco smoke and reducing sugars in tobacco blends of U.S. commercial cigarettes. Inhal Toxicol 15(4):373-395

12. Baker RR (2006) The generation of formaldehyde in cigarettesoverview and recent experiments. Food Chem Toxicol 44:17991822
13. Belluzzi JD, Wang R, Leslie FM (2005) Acetaldehyde enhances acquisition of nicotine self-administration in adolescent rats. Neuropsychopharmacology 30(4):705-712

14. Westenberger BJ (2009) Evaluation of e-cigarettes. Food and Drug Administration, Rockville

15. Burton HR (1976) Thermal decomposition and gas phase analysis of carbohydrates found in tobacco. In: Shafizadeh F, Sarkanen KV, Tillman DA (eds) Thermal uses and properties of carbohydrates and lignins. Academic, New York

16. Goniewicz MŁ, Knysak, Gawron M, Kosmider L, Sobczak A, Kurek J, Prokopowicz A, Jablonska-Czapla M, Rosik-Dulewska C, Havel C, Jacob P III, Benowitz N (2014) Levels of selected carcinogens and toxicants in vapour from electronic cigarettes. Tob Control 23:133139. doi:10.1136/tobaccocontrol-2012-050859

17. Ikegami T, Horie K, Saad N, Hosoya K, Fiehn O, Tanaka N (2008) Highly efficient analysis of underivatized carbohydrates using monolithic-silica-based capillary hydrophilic interaction (HILIC) HPLC. Anal Bioanal Chem 391(7):2533-2542

18. Perrone D, Donangelo CM, Farah A (2008) Fast simultaneous analysis of caffeine, trigonelline, nicotinic acid and sucrose in coffee by liquid chromatography-mass spectrometry. Food Chem 110:1030 1035

19. D’Arcy-Moskwa E, Westonb L, Noble GN, Raidal SL (2011) Determination of sucrose in equine serum using liquid chromatography-mass spectrometry (LC/MS). J Chromatogr B 879:3668-3671

20. Nielsen NJ, Granby K, Hedegaard RV, Skibsted LH (2006) A liquid chromatography - tandem mass spectrometry method for simultaneous analysis of acrylamide and the precursors, asparagine and reducing sugars in bread. Anal Chim Acta 557:211-220 